\title{
Modular Design via Multiple Anion Chemistry of the High Mobility van der Waals Semiconductor $\mathrm{Bi}_{4} \mathrm{O}_{4} \mathrm{SeCl}_{2}$
}

\author{
Quinn D. Gibson, ${ }^{\dagger}$ Troy D. Manning, ${ }^{\dagger}$ Marco Zanella, ${ }^{\dagger}$ Tianqi Zhao, ${ }^{\ddagger}$ Philip A. E. Murgatroyd, ${ }^{\S}$
} Craig M. Robertson, ${ }^{\dagger}$ Leanne A. H. Jones, ${ }^{\S}$ Fiona McBride, ${ }^{\dagger}$ Rasmita Raval, ${ }^{\dagger}$ Furio Cora, ${ }^{\ddagger}$ Ben Slater, ${ }^{\ddagger}$ John B. Claridge, ${ }^{\dagger}$ Vin R. Dhanak, ${ }^{\S}$ Matthew S. Dyer, ${ }^{\dagger}$ Jonathan Alaria, ${ }^{\S}$ and Matthew J. Rosseinsky ${ }^{*},{ }^{\dagger} \odot$

${ }^{\dagger}$ Department of Chemistry, University of Liverpool, Crown St, Liverpool L69 7ZD, United Kingdom

${ }^{\ddagger}$ Department of Chemistry, University College London, 20 Gordon St, Kings Cross, London WC1H 0AJ, United Kingdom

${ }^{\S}$ Department of Physics, University of Liverpool, Oxford St, Liverpool L69 7ZE, United Kingdom

\author{
Supporting Information
}

\begin{abstract}
Making new van der Waals materials with electronic or magnetic functionality is a chemical design challenge for the development of two-dimensional nanoelectronic and energy conversion devices. We present the synthesis and properties of the van der Waals material $\mathrm{Bi}_{4} \mathrm{O}_{4} \mathrm{SeCl}_{2}$, which is a $1: 1$ superlattice of the structural units present in the van der Waals insulator $\mathrm{BiOCl}$ and the threedimensionally connected semiconductor $\mathrm{Bi}_{2} \mathrm{O}_{2} \mathrm{Se}$. The presence of three anions gives the new structure both the bridging selenide anion sites that connect pairs of $\mathrm{Bi}_{2} \mathrm{O}_{2}$ layers in $\mathrm{Bi}_{2} \mathrm{O}_{2} \mathrm{Se}$ and the terminal chloride sites that produce the van der Waals gap in $\mathrm{BiOCl}$. This retains the electronic properties

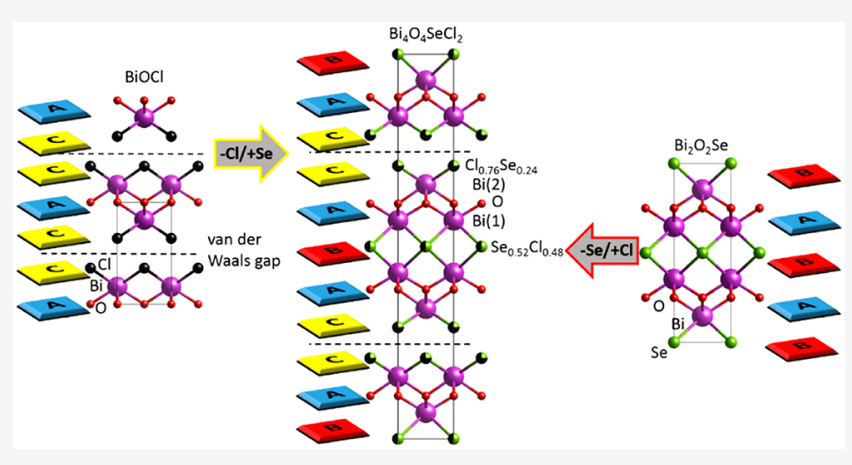
of $\mathrm{Bi}_{2} \mathrm{O}_{2} \mathrm{Se}$ while reducing the dimensionality of the bonding network connecting the $\mathrm{Bi}_{2} \mathrm{O}_{2} \mathrm{Se}$ units to allow exfoliation of $\mathrm{Bi}_{4} \mathrm{O}_{4} \mathrm{SeCl}_{2}$ to $1.4 \mathrm{~nm}$ height. The superlattice structure is stabilized by the configurational entropy of anion disorder across the terminal and bridging sites. The reduction in connective dimensionality with retention of electronic functionality stems from the expanded anion compositional diversity.
\end{abstract}

\section{INTRODUCTION}

Layered materials are built from the stacking of extended twodimensional units and can be classified according to the dimensionality of the bonding in the resulting structure. ${ }^{1}$ van der Waals materials such as semimetallic graphene, semiconducting transition metal dichalcogenides, ${ }^{2}$ and magnetic $\mathrm{RuCl}_{3}{ }^{3}$ and $\mathrm{Fe}_{3} \mathrm{GeTe}_{2}{ }^{4}$ have two-dimensional networks of strong bonds within the layers and much weaker van der Waals interactions in the third dimension between the layers. Heteroanionic systems offer a distinct path to new materials and properties tuning ${ }^{5,6}$ and have been recently put forward as a general design principle to new materials and properties tuning via affecting coordination environments and dimensionality. ${ }^{5,6}$ There are multiple anion van der Waals materials, such as $\mathrm{BiOCl}$, which has cationic antifluorite $\mathrm{Bi}_{2} \mathrm{O}_{2}{ }^{2+}$ layers bound on either side to terminal $\mathrm{Cl}^{-}$anion layers in the sequence $\mathrm{Bi}_{2} \mathrm{O}_{2}-\mathrm{Cl}-\mathrm{Cl}-\mathrm{Bi}_{2} \mathrm{O}_{2}$, forming a van der Waals gap between successive chloride layers: the material can be described as layered $\mathrm{Bi}_{2} \mathrm{O}_{2} \mathrm{Cl}_{2}$ slabs because there is no network of bonding interactions in the third dimension (Figure 1a). The van der Waals gaps allow ready exfoliation to or deposition as layers of thicknesses at or approaching those of a single unit cell. This is generally useful in the fabrication of functional heterostructures and devices, spanning electronics to energy materials. ${ }^{7,8}$
For example, high mobility two-dimensional semiconductors such as modified graphene and phosphorene have been studied intensively in nanoelectronics as field effect transistors, ${ }^{9,10}$ and the library of known two-dimensional materials has been extensively explored for potential photocatalysts. ${ }^{11}$

There are however many more layered materials where the stacked two-dimensional structural units are connected by networks of bonding interactions in the third dimension which are not interrupted by a van der Waals gap. ${ }^{1,12}$ Ionic layered materials are a subset of these three-dimensionally connected layered materials, as bonds that connect them along the third dimension are ionic in nature ( $\mathrm{LiFeAs}$ would be an example of this, with layers of $(\mathrm{FeAs})^{-}$bonded along the $c$-axis to layers of $\left.\mathrm{Li}^{+}\right) .{ }^{13}$ The semiconductor $\mathrm{Bi}_{2} \mathrm{O}_{2} \mathrm{Se}$ is also an example of such three-dimensionally connected layered materials. Here the $\mathrm{Bi}_{2} \mathrm{O}_{2}-\mathrm{Se}-\mathrm{Bi}_{2} \mathrm{O}_{2}$ layer sequence features the $\mathrm{Bi}_{2} \mathrm{O}_{2}{ }^{2+}$ layer found in $\mathrm{BiOCl}$ but now bridged by $\mathrm{Se}^{2-}$ anions bound equally to each adjacent cationic layer, forming non-van der Waals cohesive interactions in the third dimension (Figure 1b). The electronic properties of $\mathrm{Bi}_{2} \mathrm{O}_{2} \mathrm{Se}$ are however highly anisotropic due to the minimal mixing of the $\mathrm{Bi}_{2} \mathrm{O}_{2}$ states that form the

Received: August 30, 2019

Published: December 11, 2019 


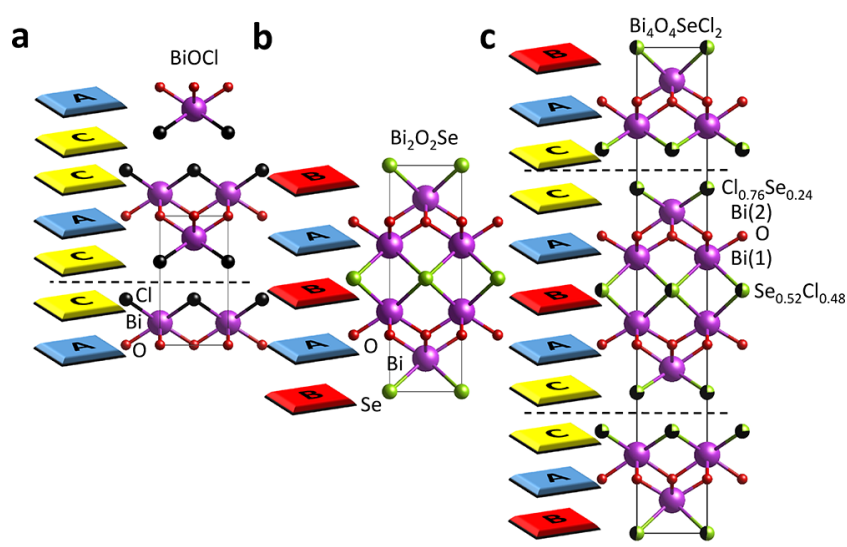

Figure 1. Building the van der Waals material $\mathrm{Bi}_{4} \mathrm{O}_{4} \mathrm{SeCl}_{2}$ from parent structural units. Comparison of the crystal structures of (a) $\mathrm{BiOCl}$ (a two-dimensionally bonded layered material held together along $c$ by van der Waals interactions), (b) $\mathrm{Bi}_{2} \mathrm{O}_{2} \mathrm{Se}$ (a three dimensionally bonded material held together along $c$ by direct bonding interactions) and (c) $\mathrm{Bi}_{4} \mathrm{O}_{4} \mathrm{SeCl}_{2}$ (a superlattice material). Dashed lines show the van der Waals gaps present in $\mathrm{BiOCl}$ and $\mathrm{Bi}_{4} \mathrm{O}_{4} \mathrm{SeCl}_{2}$, which correspond to symmetrical cleavage planes not present in $\mathrm{Bi}_{2} \mathrm{O}_{2} \mathrm{Se}$. The A-C blocks represent the common structural units in the three materials and constitute the $\mathrm{AC}_{2}$ and $\mathrm{AB}$ sequence parent materials that combine to create a new $\mathrm{A}_{2} \mathrm{BC}_{2}$ structure. The atoms are represented as $\mathrm{O}$ red, $\mathrm{Bi}$ magenta, $\mathrm{Cl}$ black, Se green.

conduction band minimum with the $4 \mathrm{p}_{z}$ states of the bridging Se. The resulting high and anisotropic electronic mobility, which is still present in ultrathin films, has placed $\mathrm{Bi}_{2} \mathrm{O}_{2} \mathrm{Se}$ under intense study as a nanoelectronic material. ${ }^{14-16}$

Chloride and selenide thus act as terminal and bridging ligands, respectively, to oxide-based $\mathrm{Bi}_{2} \mathrm{O}_{2}{ }^{2+}$ layers in twodimensionally bonded $\mathrm{BiOCl}$ and three-dimensionally connected $\mathrm{Bi}_{2} \mathrm{O}_{2} \mathrm{Se}$. By combining bridging and terminal anion chemistries in a multiple anion material, superlattices in the quaternary $\mathrm{Bi}-\mathrm{O}-\mathrm{Se}-\mathrm{Cl}$ phase field can be designed that exhibit both the electronic structure defined by the bridging anion and the van der Waals gap afforded by the terminal anion. The resulting reduction in connective dimensionality would generate a new van der Waals material with high electronic mobility that would be a candidate material for study as a new air stable $2 \mathrm{D}$ semiconductor.

\section{RESULTS AND DISCUSSION}

Reaction of $\mathrm{BiOCl}, \mathrm{Bi}, \mathrm{Bi}_{2} \mathrm{O}_{3}$, and $\mathrm{Se}$ in evacuated ampules at elevated temperatures affords phase-pure powders and single crystals of $\mathrm{Bi}_{4} \mathrm{O}_{4} \mathrm{SeCl}_{2}$, which contains all three anions. This composition had been previously identified in a gas-phase reactivity study as forming a phase, without reported crystal structure or properties. ${ }^{17}$ The refined structural parameters from a crystal grown at $800{ }^{\circ} \mathrm{C}$ are given in Supplementary Tables 1-6, and the structure is shown in Figure 1c. $\mathrm{Bi}_{4} \mathrm{O}_{4} \mathrm{SeCl}_{2}$ adopts a layered structure based on the antifluorite $\mathrm{Bi}_{2} \mathrm{O}_{2}{ }^{2+}$ layers (denoted A in Figure 1) characteristic of both van der Waals $\mathrm{BiOCl}\left(\mathrm{AC}_{2}\right.$ layer sequence, where $\mathrm{C}$ is a $\mathrm{Cl}^{-}$ layer) and layered $\mathrm{Bi}_{2} \mathrm{O}_{2} \mathrm{Se}$ ( $\mathrm{AB}$ layer sequence, where $\mathrm{B}$ is an $\mathrm{Se}^{2-}$ layer). The structure of $\mathrm{Bi}_{4} \mathrm{O}_{4} \mathrm{SeCl}_{2}$ can be considered as an $\mathrm{A}_{2} \mathrm{BC}_{2}$ 1:1 superlattice of $\mathrm{AB}$ and $\mathrm{AC}_{2}$ slabs present in the parent compounds $\mathrm{Bi}_{2} \mathrm{O}_{2} \mathrm{Se}$ and $\mathrm{BiOCl}$, respectively, resulting in a $\mathrm{Bi}_{2} \mathrm{O}_{2}-\mathrm{Se}-\mathrm{Bi}_{2} \mathrm{O}_{2}-\mathrm{Cl}-\mathrm{Cl}-\mathrm{Bi}_{2} \mathrm{O}_{2}$ layer sequence. The introduction of the two successive $\mathrm{Cl}^{-}(\mathrm{C})$ layers produces the van der Waals gap in $\mathrm{Bi}_{4} \mathrm{O}_{4} \mathrm{SeCl}_{2}$. In this construction, the $\mathrm{B}$ and $\mathrm{C}$ slabs are not defined by the anion present, but rather the bridging and terminal nature of the slab, respectively.

The environment of the $\mathrm{Bi}_{2} \mathrm{O}_{2}{ }^{2+}$ unit is asymmetric, in contrast to both parent structures, as on one side there is the single bridging anion $\mathrm{Se}^{2-}$ layer present in $\mathrm{Bi}_{2} \mathrm{O}_{2} \mathrm{Se}$ that connects to a neighboring $\mathrm{Bi}_{2} \mathrm{O}_{2}{ }^{2+}$ layer, whereas on the other there are two successive layers of terminally bound chloride anions characteristic of $\mathrm{BiOCl}$. This creates the symmetrical cleavage plane in $\mathrm{Bi}_{4} \mathrm{O}_{4} \mathrm{SeCl}_{2}$ (Figure 1c), which separates the two halves of the unit cell without breaking bonds. $\mathrm{Bi}_{2} \mathrm{O}_{2} \mathrm{Se}$, by contrast, does not have such a plane, as its layered structural units share bridging atoms producing a three-dimensional network of bonds. The bridging $\mathrm{Se}$ in $\mathrm{Bi}_{4} \mathrm{O}_{4} \mathrm{SeCl}_{2}$ still connects two neighboring $\mathrm{Bi}_{2} \mathrm{O}_{2}{ }^{2+}$ cationic layers, but the van der Waals gap prevents further extension of bonding interactions along $c$. The structure can then be represented as charge-neutral $\mathrm{Bi}_{4} \mathrm{O}_{4} \mathrm{SeCl}_{2}$ slabs of thickness $1.40 \mathrm{~nm}$ (Figure $2 \mathrm{a}$ ), stacked by van der Waals forces in the $c$ direction.

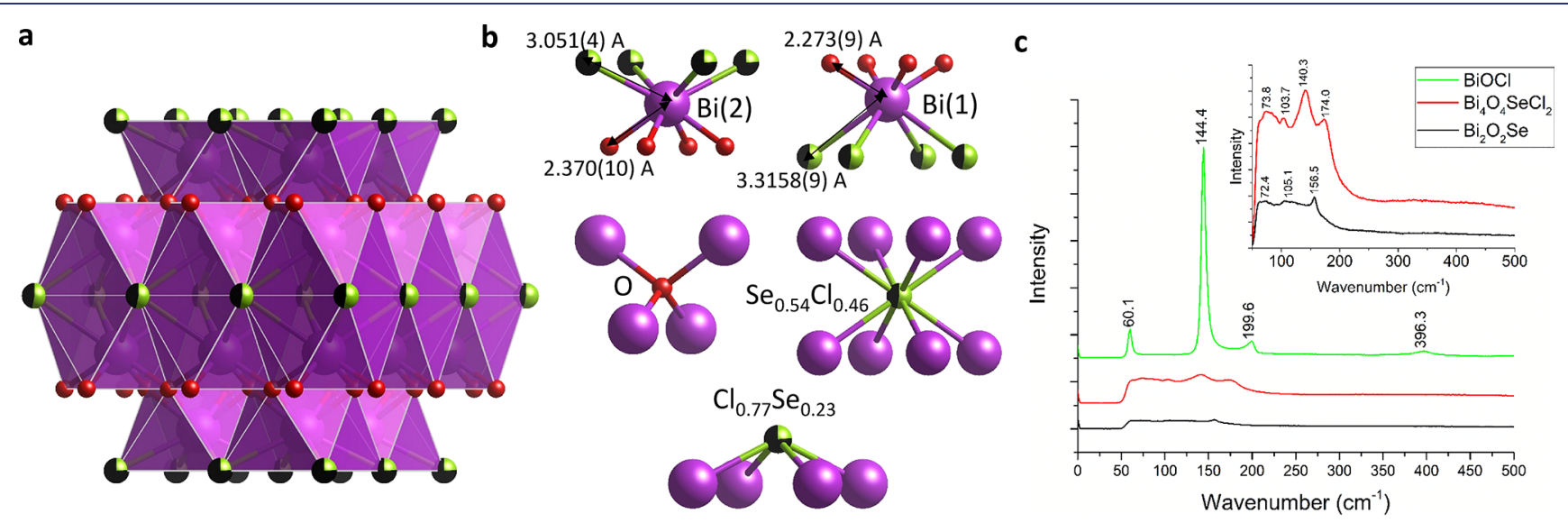

Figure 2. Multiple anion bonding environments form a composite charge-neutral slab in $\mathrm{Bi}_{4} \mathrm{O}_{4} \mathrm{SeCl}_{2}$. (a) Representation of the crystal structure of $\mathrm{Bi}_{4} \mathrm{O}_{4} \mathrm{SeCl}_{2}$, showing the $\mathrm{Bi}$ coordination polyhedra, which highlights the charge-neutral $\mathrm{Bi}_{4} \mathrm{O}_{4} \mathrm{SeCl}_{2}$ van der Waals slabs. (b) Coordination environments for the two cation and three anion sites in $\mathrm{Bi}_{4} \mathrm{O}_{4} \mathrm{SeCl}_{2}$. (c) Raman spectra of single crystal flakes of $\mathrm{BiOCl}_{1} \mathrm{Bi}_{2} \mathrm{O}_{2} \mathrm{Se}_{2}$ and $\mathrm{Bi}_{4} \mathrm{O}_{4} \mathrm{SeCl}_{2}$. Both the incident and measured beam were normal to the crystal surface. Some relevant peaks are denoted by the wavenumber of their maximum intensity. The atoms are represented as $\mathrm{O}$ red, Bi magenta, $\mathrm{Cl}$ black, Se green 

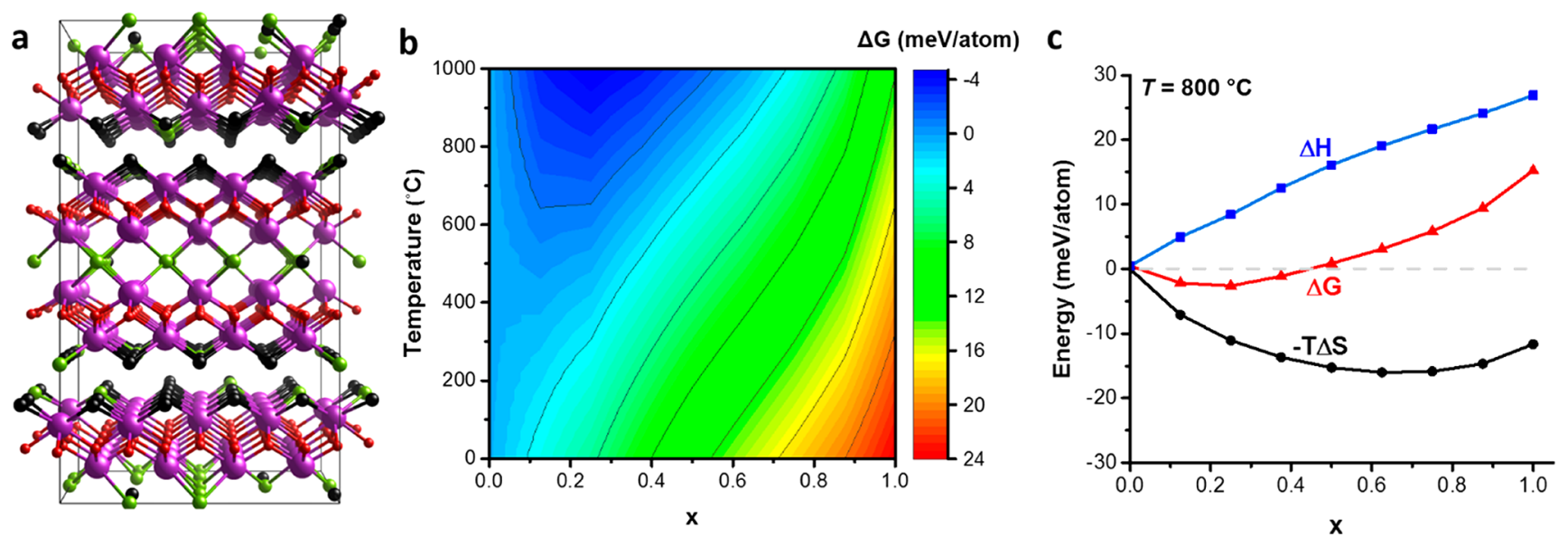

Figure 3. Stabilization of the superlattice phase $\mathrm{Bi}_{4} \mathrm{O}_{4} \mathrm{SeCl}_{2}$ via configurational entropy from anion mixing. (a) Representative optimized superstructure of $\mathrm{Bi}_{4} \mathrm{O}_{4} \mathrm{SeCl}_{2}$, for a level of anion site occupancy disorder corresponding to $x=3 / 8$, showing the distribution of Se/Cl defects. Other optimized superstructures are shown in Supplementary Figure 6. (b) $\Delta G$ for reaction 1 versus $T$ and the anion site occupancy disorder parameter $x$, indicating regions at which formation is spontaneous. At any given $T$, the minimum in $\Delta G$ corresponds to the expected equilibrium value for $x$. At $x=0$, the value for $\Delta G$ is slightly positive for all $T$. This map was constructed by interpolating between the discrete calculated points at intervals of $1 / 8$ for $x$. (c) Plot of $\Delta H,-T \Delta S$, and $\Delta G$ for reaction $1: \mathrm{Bi}_{2} \mathrm{O}_{2} \mathrm{Se}+2 \mathrm{BiOCl}_{\rightarrow} \mathrm{Bi}_{4} \mathrm{O}_{4} \mathrm{SeCl}_{2}$ (as represented by $\mathrm{Bi}_{2} \mathrm{O}_{2} \mathrm{Se}_{1-\mathrm{x}} \mathrm{Cl}_{\mathrm{x}} \mathrm{Bi}_{2} \mathrm{O}_{2} \mathrm{Cl}_{2-\mathrm{x}} \mathrm{Se}_{\mathrm{x}}$ where $\mathrm{x}$ is a metric of the se for $\mathrm{Cl}$ substitution across the two slab types) as a function of $x$ at $800{ }^{\circ} \mathrm{C}$.

There is significant anion mixing across the bridging and terminal sites, such that the composition of the bridging layer is $\mathrm{Se}_{0.52(2)} \mathrm{Cl}_{0.48(2)}$ and that of the terminal bilayer is $\mathrm{Cl}_{1.516(26)} \mathrm{Se}_{0.484(26)}$, respectively. The layers will be referred to as the $\mathrm{Se}(\mathrm{Cl})$ layer and $(\mathrm{Cl}(\mathrm{Se}))_{2}$ layers in what follows. The two alternating anion layers produce two different square antiprismatic $\mathrm{Bi}$ environments on either side of the $\mathrm{Bi}_{2} \mathrm{O}_{2}{ }^{2+}$ unit; while both $\mathrm{Bi}$ sites are coordinated to four oxide and four nonoxide anions, due to the different nature of the $\mathrm{Se}(\mathrm{Cl})$ and $(\mathrm{Cl}(\mathrm{Se}))_{2}$ layers, the bond lengths at the two sites are markedly different (Figure 2b). The $2.360(6) \AA \mathrm{Bi}(2)-\mathrm{O}$ bond is elongated compared to $\mathrm{Bi}(1)-\mathrm{O}(2.272(5) \AA)$, while the $3.041(2) \AA \mathrm{Bi}(2)-\mathrm{Cl}(\mathrm{Se})$ bond is significantly shorter than the $\mathrm{Bi}(1)-\mathrm{Se}(\mathrm{Cl})$ bond $(3.3085(5) \AA)$. The four elongated $\mathrm{Bi}(2)-\mathrm{O}$ bonds correspond to four shorter bonds between $\mathrm{Bi}(2)$ and the terminal anion site. These variations reflect the asymmetrical bonding at the cation and anion sites: the terminal $\mathrm{Cl}(\mathrm{Se})$ anion site only makes four bonds to $\mathrm{Bi}(2)$ and is repelled from the neighboring $\mathrm{Cl}(\mathrm{Se})$ site in the adjacent anion layer, with both effects shortening the bond compared to $\mathrm{Bi}(1)-\mathrm{Se}(\mathrm{Cl})$ where the bridging anion bonds equally to eight $\mathrm{Bi}(1)$ cations on either side. This difference in anion coordination environment is fundamentally linked to the presence or absence of the van der Waals gap. The difference in bond length is more associated with the different anion coordination environment than ionic radii, and it is consistent with the bond lengths in the parent materials $\mathrm{BiOCl}(\mathrm{Bi}-\mathrm{Cl}=$ 3.059(9) $\AA$ ) and $\mathrm{Bi}_{2} \mathrm{O}_{2} \mathrm{Se}(\mathrm{Bi}-\mathrm{Se}=3.272(17) \AA)$. This $\mathrm{Bi}-\mathrm{Se}$ bond length in $\mathrm{Bi}_{2} \mathrm{O}_{2} \mathrm{Se}$ and the $\mathrm{Bi}(1)-\mathrm{Se}(\mathrm{Cl})$ bond length in $\mathrm{Bi}_{4} \mathrm{O}_{4} \mathrm{SeCl}_{2}$ are $0.24 \AA$ longer than the longest $\mathrm{Bi}-\mathrm{Se}$ bond in $\mathrm{Bi}_{2} \mathrm{Se}_{3},{ }^{18}$ indicating that this bond is relatively weak and ionic. Electronic structure calculations presented later in Figure 4 show that covalent bonding interactions do exist between these ions. $\mathrm{Bi}_{2} \mathrm{O}_{2} \mathrm{Se}$ can then be considered to have threedimensional connectivity arising from both ionic and covalent interactions, in contrast to $\mathrm{BiOCl}$, where the van der Waals gap between the two successive $\mathrm{Cl}$ layers prevents three-dimensional connectivity. The fundamental difference in connectivity is further explored in the Supporting Information (Supple- mentary Tables 13 and 14, Supplementary Figure 9), where density functional theory demonstrates the direct bonding nature of the $\mathrm{Bi}-\mathrm{Se}-\mathrm{Bi}$ interface and the dispersive interaction (van der Waals bonding) nature of the $\mathrm{Bi}-\mathrm{Cl}-\mathrm{Cl}-\mathrm{Bi}$ interface. This difference in connectivity has a significant impact on the exfoliation energy, as explored in Figure 7.

Each of the three anion sites in $\mathrm{Bi}_{4} \mathrm{O}_{4} \mathrm{SeCl}_{2}$ has a unique bonding environment (Figure 2b). The oxygen in all of the compounds discussed is tetrahedrally coordinated to $\mathrm{Bi}$; the parent materials have the same $\mathrm{Bi}-\mathrm{O}$ bond lengths, within error, of 2.3165(13) and 2.312(17) $\AA$ for $\mathrm{BiOCl}$ and $\mathrm{Bi}_{2} \mathrm{O}_{2} \mathrm{Se}$, respectively, which is a value in between the two $\mathrm{Bi}-\mathrm{O}$ bond lengths observed in $\mathrm{Bi}_{4} \mathrm{O}_{4} \mathrm{SeCl}_{2}$. The asymmetry of the two sides of the $\mathrm{Bi}_{2} \mathrm{O}_{2}$ unit in $\mathrm{Bi}_{4} \mathrm{O}_{4} \mathrm{SeCl}_{2}$ thus changes the oxygen environment compared to the parent structures. Due to the retention of the site chemistries and atomic positions seen in the structural units of $\mathrm{Bi}_{2} \mathrm{O}_{2} \mathrm{Se}$ and $\mathrm{BiOCl}, \mathrm{Bi}_{4} \mathrm{O}_{4} \mathrm{SeCl}_{2}$ can be described as a $1: 1$ superlattice of these structural units, with $\mathrm{Se} / \mathrm{Cl}$ mixing allowed on the distinct structural sites within the material, with assignment of the $\mathrm{B}$ and $\mathrm{C}$ structural units as shown in Figure 1.

The Raman spectrum (Figure $2 \mathrm{c}$ ) of large platelike $(\sim 5 \mathrm{~mm}$ $\times 5 \mathrm{~mm}$ ) single crystals grown by chemical vapor transport (Supporting Information) of $\mathrm{Bi}_{4} \mathrm{O}_{4} \mathrm{SeCl}_{2}$ exhibits features seen in the Raman spectra of single crystals of both the parent materials $\mathrm{Bi}_{2} \mathrm{O}_{2} \mathrm{Se}$ and $\mathrm{BiOCl}$, and is consistent with the presence of the same total set of bonding interactions, together with some extra features, likely due to the new $\mathrm{Bi}-\mathrm{Se}$ and $\mathrm{Bi}-$ $\mathrm{Cl}$ bonds present from the $\mathrm{Se} / \mathrm{Cl}$ disorder. Previous Raman studies of $\mathrm{Bi}_{2} \mathrm{O}_{2} \mathrm{Se}$ have shown broad peaks starting from 59 $\mathrm{cm}^{-1}$ along with a sharp peak at $159.2 \mathrm{~cm}^{-1}$, which was assigned to an interlayer breathing mode, ${ }^{19}$ which is not observed in this case due to the beam being perpendicular to the single crystal surface.

The formation of $\mathrm{Bi}_{4} \mathrm{O}_{4} \mathrm{SeCl}_{2}$ from the parent materials was considered by calculation of the free energy of reaction 1 over the temperature range $0 \leq T /{ }^{\circ} \mathrm{C} \leq 1000$, where the entropy change is assumed to be purely due to configurational entropy.

$$
\mathrm{Bi}_{2} \mathrm{O}_{2} \mathrm{Se}+2 \mathrm{BiOCl} \rightarrow \mathrm{Bi}_{4} \mathrm{O}_{4} \mathrm{SeCl}_{2}
$$



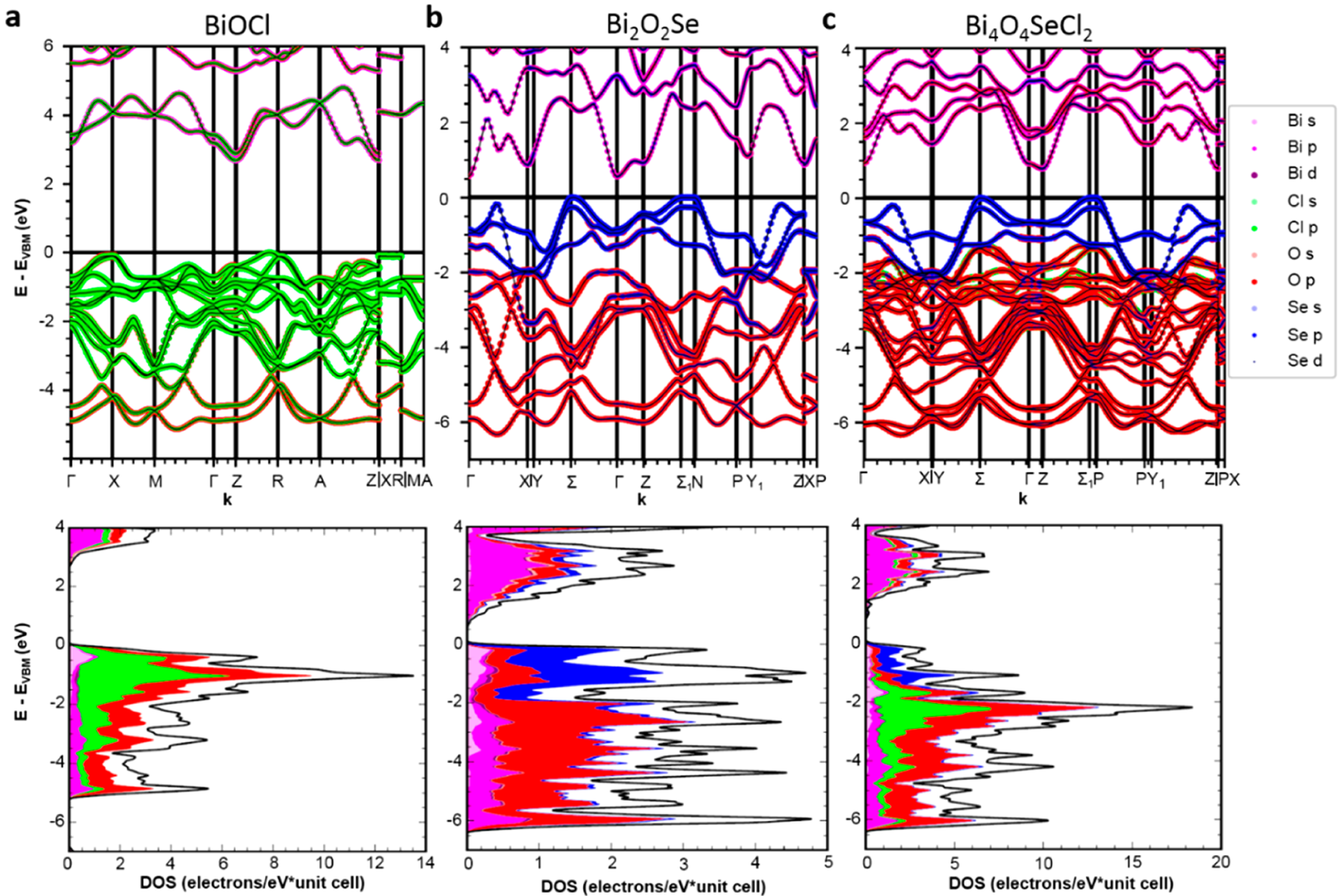

Figure 4. Electronic structure of $\mathrm{Bi}_{4} \mathrm{O}_{4} \mathrm{SeCl}_{2}$ : Relationship to $\mathrm{BiOCl}$ and $\mathrm{Bi}_{2} \mathrm{O}_{2} \mathrm{Se}$. Electronic band structures (top) and density of states plots (bottom) for (a) $\mathrm{BiOCl}$, (b) $\mathrm{Bi}_{2} \mathrm{O}_{2} \mathrm{Se}$, and (c) $\mathrm{Bi}_{4} \mathrm{O}_{4} \mathrm{SeCl}_{2}$ at the SCAN + SOC + vdW level of theory. The colors correspond to the atomic orbitals that contribute to the states at that point.

Here $\mathrm{Bi}_{4} \mathrm{O}_{4} \mathrm{SeCl}_{2}$ is described in terms of the component structural units $\left(\mathrm{Bi}_{2} \mathrm{O}_{2} \mathrm{Se}_{1-x} \mathrm{Cl}_{x}\right)\left(\mathrm{Bi}_{2} \mathrm{O}_{2} \mathrm{Cl}_{2-\mathrm{x}} \mathrm{Se}_{x}\right)$ where the mixing parameter $x$ describes the level of Se/Cl disorder. $x=$ 0 corresponds to perfect order, and the refined experimental structure corresponds to $x=0.48(2)$. Supercells were constructed from disordered structures as described in the Supporting Information, with a representative structure shown for $x=3 / 8$ in Figure 3a.

Within these approximations, reaction 1 is not spontaneous at perfect anion site order $(x=0, \Delta G=+0.46 \mathrm{meV} /$ atom $)$. The $\mathrm{Cl} / \mathrm{Se}$ anion site substitutional disorder increases the enthalpy of the product, but this is offset by the increase in configurational entropy leading to a negative $\Delta G$ for a wide range of $\mathrm{x}$ (Figure $3 \mathrm{~b}$ ). At $T=800{ }^{\circ} \mathrm{C}$, the minimum of $\Delta G$, where the reaction would come to equilibrium, occurs at $x=$ 0.21 and the zero crossing occurs at $x=0.43$, past which the formation of the phase is not thermodynamically favored compared to the parent compounds (Figure 3c). This equilibrium value of 0.21 is lower than the experimental value of $0.48(2)$, assigned to overestimation of the enthalpy due to the finite supercells used for the calculation.

Because the enthalpy of the defect formation is very small (on the order $10 \mathrm{meV} /$ atom), the configurational entropy can become a significant stabilizing effect to allow the reaction to proceed. The anion mixing will produce partial charges on each layer, with the resulting charge distribution in each van der Waals slab of $\left(\mathrm{Cl}_{1-x / 2} \mathrm{Se}_{x / 2}\right)^{x / 2-}\left(\mathrm{Bi}_{2} \mathrm{O}_{2}\right)\left(\mathrm{Se}_{1-x} \mathrm{Cl}_{x}\right)^{x+}\left(\mathrm{Bi}_{2} \mathrm{O}_{2}\right)$ $\left(\mathrm{Cl}_{1-x / 2} \mathrm{Se}_{x / 2}\right)^{x / 2-}$, where the layer charge quoted is the difference in charge from the perfectly anion-ordered case. The $\mathrm{Cl} / \mathrm{Se}$ disorder only generates a quadrupolar charge distribution in each van der Waals slab, and the monotonic increase in $\Delta H$ as a function of $x$ rules out the electrostatic interaction as being the stabilizing effect for superlattice formation. The stabilizing entropy arises not from solid solution mixing on sites within a known structure, as in the high entropy alloys and oxides, ${ }^{20,21}$ but through the creation of two distinct anion sites between the $\mathrm{Bi}_{2} \mathrm{O}_{2}{ }^{2+}$ layers by the superlattice formation. This creates an "entropy-stabilized superlattice" through cross-substitution between the sites in the component blocks. While it is possible that other stabilizing interactions are missed by the choice of the supercell, at this level of theory it is clear that the configurational entropy of mixing plays a significant role in stabilizing the formation of the phase.

This modular approach to building a layered structure is related to recently reported homologous series, ${ }^{22,23}$ and especially to the family of Sillen-Aurivilius phases, a large materials family which contains $\mathrm{Bi}_{2} \mathrm{O}_{2}$ Se-like $\mathrm{Bi}_{2} \mathrm{O}_{2} \mathrm{Cl}$ charged blocks along with perovskite-like metal oxide layers in order to charge balance and has been explored as ferroelectric and photocatalytic materials. ${ }^{24,25} \mathrm{Bi}_{4} \mathrm{O}_{4} \mathrm{SeCl}_{2}$ represents a different and complementary approach to generating new structures that combines two otherwise charge neutral slabs and three different types of anion environments with a single cation. Here two modules have been put together via an entropy stabilization effect, yielding a three anion material with one cation, formed from two layered parent materials, and the first reported structure in the $\mathrm{Bi}-\mathrm{Se}-\mathrm{O}-\mathrm{Cl}$ field, where $\mathrm{Se}, \mathrm{O}, \mathrm{Cl}$ are all anions. 
The layer sequence in $\mathrm{Bi}_{4} \mathrm{O}_{4} \mathrm{SeCl}_{2}$ places a large band gap $\mathrm{BiOCl}$ unit on either side of the $\mathrm{Bi}_{2} \mathrm{O}_{2}$ Se layer. The electronic band structure of $\mathrm{Bi}_{4} \mathrm{O}_{4} \mathrm{SeCl}_{2}$ has both conduction and valence bands derived from the $\mathrm{Bi}_{2} \mathrm{O}_{2} \mathrm{Se}$ layer, consistent with the calculated band positions in the parent materials (Figure 4). The states of the more electronegative $\mathrm{Cl}$ lie below those of $\mathrm{Se}$ in the valence band. The lowest lying unoccupied states are derived from the $\mathrm{Bi}(1)$ site bound to the bridging Se anion, because at high symmetry k-points, such as the bottom of the conduction band at $\Gamma$, the Se p states cannot, by symmetry, form bonding or antibonding states with both sets of equivalent $\mathrm{Bi}(1)$ sites that lie on either side. Therefore, the states at the conduction band minimum are $\mathrm{Bi}(1)-\mathrm{Se}$ nonbonding and composed purely of $\mathrm{Bi} 6 \mathrm{p}$-derived $\mathrm{Bi}(1)-\mathrm{O}$ antibonding states from the $\mathrm{Bi}_{2} \mathrm{O}_{2}{ }^{2+}$ slab. This symmetry constraint does not apply to the terminal $\mathrm{Cl}$ site, which has $\mathrm{Bi}(2)$ only on one side and therefore can form bonding/ antibonding interactions at all k-points, leading to an antibonding interaction at $\Gamma$, placing the $\mathrm{Bi}(2)-\mathrm{O}$ states interacting with $\mathrm{Cl}$ at higher energy than the $\mathrm{Bi}(1)-\mathrm{O}$ states, which are forbidden by symmetry from interacting with Se and thus less antibonding. While the conduction band minimum is mainly formed of $\mathrm{Bi} 6 \mathrm{p}$ and $\mathrm{O}$ states, the level of mixing with the $\mathrm{Se} / \mathrm{Cl}$ anion $\mathrm{p}$ states as determined by symmetry is what leads to a small $(<1 \mathrm{eV})$ shift in energy of these $\mathrm{Bi} 6 \mathrm{p}-\mathrm{O}$ states. A full symmetry analysis of the relevant orbitals is shown in Supplementary Table 8. It is notable, however, that antibonding interactions are allowed at other k-points and, especially in bands more than $2 \mathrm{eV}$ above $E_{\mathrm{F}}$, significant $\mathrm{Bi}$ $6 \mathrm{p}-\mathrm{Se} 4 \mathrm{p}$ mixing is observed in the electronic structure, indicating covalent interactions between these ions. This is further confirmed by noting that these bands are heavily affected by the Se/Cl disorder (Supplementary Figure 7).

This picture is confirmed by projection of the orbitals from the two Bi sites onto the bands (Supplementary Figure 8), showing that the highest occupied and lowest unoccupied states are dominated by $\mathrm{Bi}(1)$. The distinct terminal and bridging anion chemistries result in two lowest unoccupied bands which have not only different energies but different dispersions because of the different bonding modes at the $\mathrm{Bi}(1)$ and $\mathrm{Bi}(2)$ sites. $\mathrm{Bi}(1)-\mathrm{Se}$ bonding and antibonding interactions do form at lower symmetry k-points and thus are still important for the cohesive interactions. $\mathrm{Bi}_{4} \mathrm{O}_{4} \mathrm{SeCl}_{2}$ is experimentally determined to be an n-type semiconductor (Figure 5), so the properties of the conduction band control charge transport.

Because the conduction band dispersion at and near the minimum is dominated by in-plane interactions between $\mathrm{Bi}(1)$ $6 \mathrm{p}$ states, it is highly two-dimensional, to an even greater extent than $\mathrm{Bi}_{2} \mathrm{O}_{2}$ Se because the terminal $\mathrm{Cl}$ more strongly attenuate the $\mathrm{Bi}-\mathrm{Bi}$ interactions along $\mathrm{c}$. This band narrowing results in an increase in the computed (HSE06) gap from $1.00 \mathrm{eV}$ (indirect, near IR) in $\mathrm{Bi}_{2} \mathrm{O}_{2}$ Se to $1.25 \mathrm{eV}$ (indirect, visible) in $\mathrm{Bi}_{4} \mathrm{O}_{4} \mathrm{SeCl}_{2}$, both considerably smaller than in $\mathrm{BiOCl}$ (3.41 $\mathrm{eV}$ ) where the bands are separated by the $\mathrm{Bi}-\mathrm{Cl}$ bonding.

That both the valence band maximum and conduction band minimum in $\mathrm{Bi}_{4} \mathrm{O}_{4} \mathrm{SeCl}_{2}$ derive from the $\mathrm{Bi}_{2} \mathrm{O}_{2} \mathrm{Se}$ slab is reflected in the effective masses. The in-plane electron effective masses are $0.20(1) m_{\mathrm{e}}, 0.17(1) m_{\mathrm{e}}$, and $0.41(1) m_{\mathrm{e}}$ for $\mathrm{Bi}_{4} \mathrm{O}_{4} \mathrm{SeCl}_{2}, \mathrm{Bi}_{2} \mathrm{O}_{2} \mathrm{Se}$, and $\mathrm{BiOCl}$, respectively, with out-ofplane electron effective masses of $0.65(1) m_{\mathrm{e}}, 0.44(1) m_{\mathrm{e}}$, and 0.69(1) $m_{\mathrm{e}}$. Therefore, the conduction band of $\mathrm{Bi}_{4} \mathrm{O}_{4} \mathrm{SeCl}_{2}$ thus behaves like that of $\mathrm{Bi}_{2} \mathrm{O}_{2} \mathrm{Se}$ in-plane and that of $\mathrm{BiOCl}$ out-of-
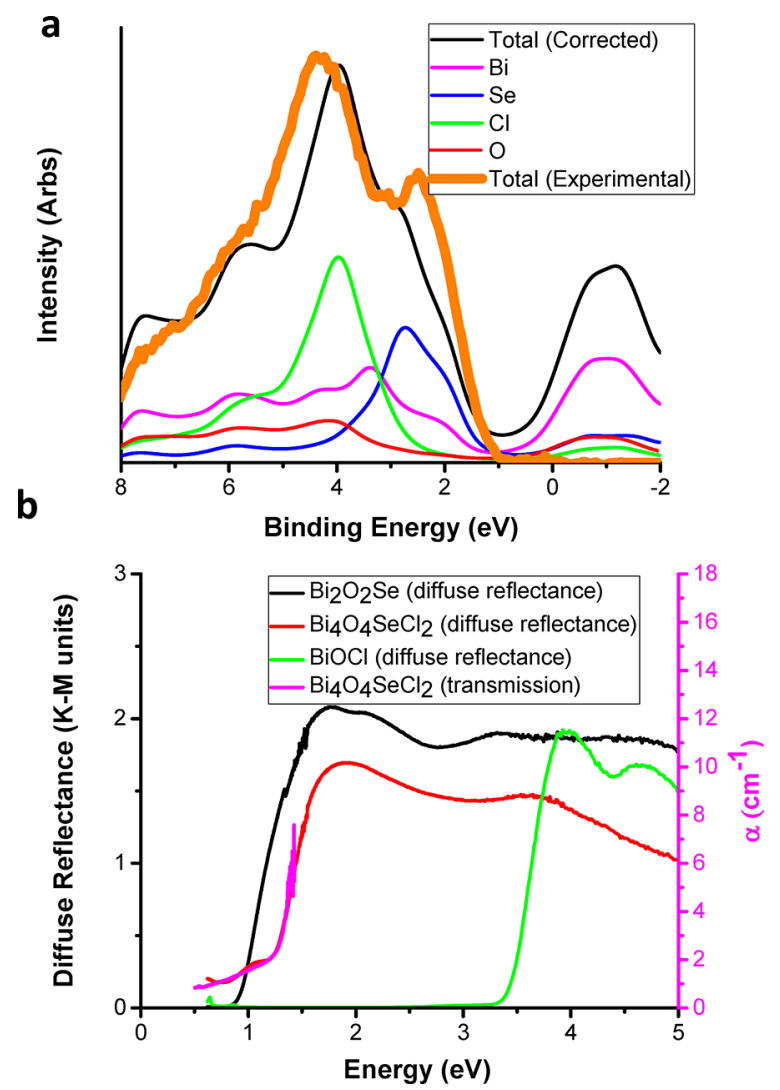

Figure 5. Experimental characterization of electronic structure of $\mathrm{Bi}_{4} \mathrm{O}_{4} \mathrm{SeCl}_{2}$. (a) Valence band XPS of $\mathrm{Bi}_{4} \mathrm{O}_{4} \mathrm{SeCl}_{2}$, compared with the calculated density of states (total and atomic), as corrected with orbital-dependent cross sections and instrumental broadening factors. (b) Diffuse reflectance of powdered $\mathrm{Bi}_{4} \mathrm{O}_{4} \mathrm{SeCl}_{2}$ (red), $\mathrm{Bi}_{2} \mathrm{O}_{2} \mathrm{Se}$ (black), and $\mathrm{BiOCl}$ (green) and absorbance of a $\mathrm{Bi}_{4} \mathrm{O}_{4} \mathrm{SeCl}_{2}$ single crystal (magenta), as calculated from the transmission.

plane. Similarly to the electron states, the hole states of $\mathrm{Bi}_{4} \mathrm{O}_{4} \mathrm{SeCl}_{2}$ in-plane are like those in $\mathrm{Bi}_{2} \mathrm{O}_{2} \mathrm{Se}$ but are heavier out-of-plane (Supplementary Tables 11 and 12). The hole states for $\mathrm{BiOCl}$ fundamentally differ from either $\mathrm{Bi}_{4} \mathrm{O}_{4} \mathrm{SeCl}_{2}$ and $\mathrm{Bi}_{2} \mathrm{O}_{2}$ Se as they originate from mixed $\mathrm{O}$ and $\mathrm{Cl}$ orbitals.

Electronic structure calculations of an anion site-disordered supercell with $x=3 / 8$ show that the disorder significantly smears out the valence band manifold while the conduction band is almost unchanged (Supplementary Figure 7). The conduction band minimum is only weakly affected by the Se/ $\mathrm{Cl}$ disorder, as the bridging anion is nonbonding at those $\mathrm{k}$ points and the resulting wave functions are derived from $\mathrm{Bi}(1)$ $\mathrm{O}$ orbitals. Thus, even in the presence of anion site disorder, $\mathrm{Bi}_{4} \mathrm{O}_{4} \mathrm{SeCl}_{2}$ should retain the in-plane electron transport features of $\mathrm{Bi}_{2} \mathrm{O}_{2} \mathrm{Se}$ with enhanced anisotropy arising from the reduced bonding dimensionality associated with the van der Waals gap introduced by the $\mathrm{BiOCl}$ layer.

XPS measurements were performed on $\mathrm{Bi}_{4} \mathrm{O}_{4} \mathrm{SeCl}_{2}$ to experimentally determine the density of states (Figure 5a). To compare the experimental data with the calculated DOS, orbital dependent photoionization cross sections ${ }^{26}$ and a Gaussian instrumental correction were applied to the calculations (Supporting Information). These data show good agreement, with some discrepancies which may arise from the $\mathrm{Se} / \mathrm{Cl}$ disorder as discussed earlier. The material is $\mathrm{n}$ type and the gap from the valence band to conduction band edge is measured as $1.2 \mathrm{eV}$. 
The experimental optical band gaps were measured on powders of $\mathrm{Bi}_{4} \mathrm{O}_{4} \mathrm{SeCl}_{2}$ and the parent materials $\mathrm{Bi}_{2} \mathrm{O}_{2} \mathrm{Se}$ and $\mathrm{BiOCl}$ by diffuse reflectance spectroscopy (Figure $5 \mathrm{~b}$ ). Comparison of the Kubelka-Munk transform of the reflectivity shows that the indirect gap of $\mathrm{Bi}_{4} \mathrm{O}_{4} \mathrm{SeCl}_{2}$ is moved to higher energy of 1.15(5) eV from the $0.87(5) \mathrm{eV}$ of $\mathrm{Bi}_{2} \mathrm{O}_{2} \mathrm{Se}$. The gap of $\mathrm{BiOCl}$ is much larger $(3.30(5) \mathrm{eV}$ ), consistent with the electronic structure calculations. The gap values, and the $0.25 \mathrm{eV}$ increase from $\mathrm{Bi}_{2} \mathrm{O}_{2} \mathrm{Se}$ to the $\mathrm{Bi}_{4} \mathrm{O}_{4} \mathrm{SeCl}_{2}$ superlattice, are close to the predictions of the HSE06 hybrid functional. Fitting the direct gap leads to a larger gap of $1.35(5) \mathrm{eV}$, indicating that the smaller gap is the indirect one, consistent with the electronic structure calculations. The measured gap was confirmed by transmission measurements on large single crystals of $\mathrm{Bi}_{4} \mathrm{O}_{4} \mathrm{SeCl}_{2}$ (Figure $5 \mathrm{~b})$, which also gave an indirect gap of $1.15 \mathrm{eV}$, consistent with the XPS and reflectivity results.

The electronic transport properties measured on a single crystal of $\mathrm{Bi}_{4} \mathrm{O}_{4} \mathrm{SeCl}_{2}$ are shown in Figure 6a. The temperature
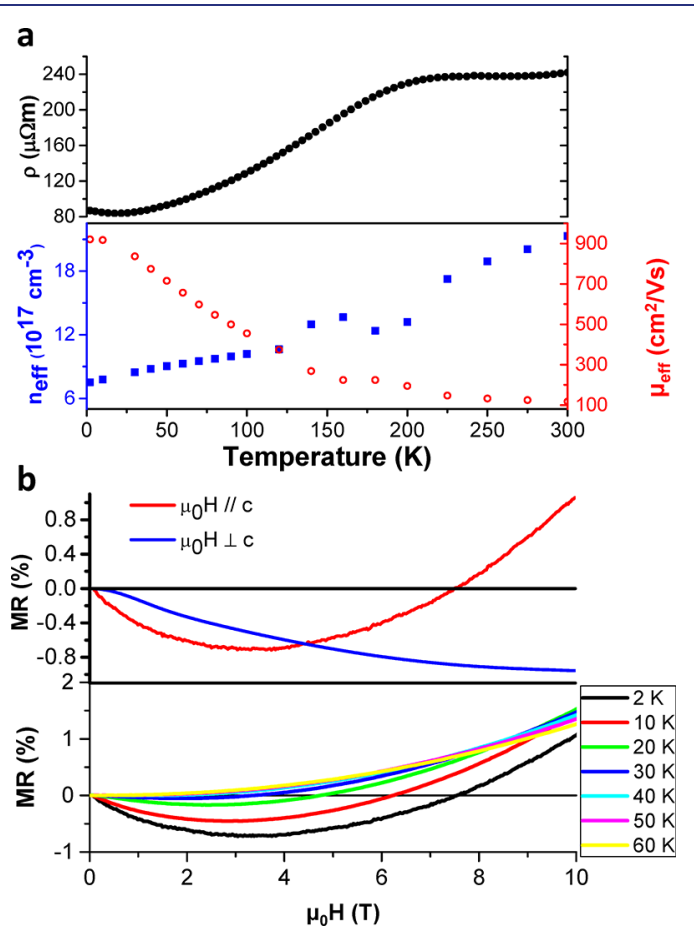

Figure 6. Electronic properties of single crystal $\mathrm{Bi}_{4} \mathrm{O}_{4} \mathrm{SeCl}_{2}$. (a) Resistivity (black dots), carrier concentration (blue squares), and mobility (red circles) as a function of temperature measured on a $\mathrm{Bi}_{4} \mathrm{O}_{4} \mathrm{SeCl}_{2}$ single crystal. All measurements were performed with the current in the $a b$ plane of the crystal. (b) Top: Magnetoresistance measured at $2 \mathrm{~K}$ with the magnetic field parallel (red line) and perpendicular (blue line) to the $c$ axis. The current is in the $a b$ plane of the crystal. Bottom: Magnetoresistance as a function of applied field (along $c$ ) at various temperatures, showing the emergence of classical parabolic behavior at $60 \mathrm{~K}$. The response at lower temperatures results from quantum mechanical weak localization effects.

dependence of the resistivity (top panel of Figure 6a) is typical of a degenerate semiconductor which is mobility, rather than carrier concentration, controlled (bottom panel of Figure 6a) and decreases with temperature down to $10 \mathrm{~K}$. The effective carrier concentration at $300 \mathrm{~K}$ is $2.1(2) \times 10^{18} \mathrm{~cm}^{-3}$ and decreases slightly as the temperature is decreased, as expected for a degenerate semiconductor. The Hall mobility measured at $300 \mathrm{~K}$ is $117(1) \mathrm{cm}^{2} /(\mathrm{V} \mathrm{s})$ which is comparable to the field effect mobility $\left(140 \mathrm{~cm}^{2} /(\mathrm{V} \mathrm{s})\right)$ measured in a similar band gap two-dimensional $(1.34 \mathrm{eV})$ material $\mathrm{WSe}_{2}{ }^{27}$ as well as the Hall mobility of ultrathin devices of the parent material $\mathrm{Bi}_{2} \mathrm{O}_{2} \mathrm{Se}\left(\sim 100 \mathrm{~cm}^{2} /(\mathrm{V} \mathrm{s})\right):{ }^{16}$ the Hall mobility of $\mathrm{Bi}_{4} \mathrm{O}_{4} \mathrm{SeCl}_{2}$ reaches $920(1) \mathrm{cm}^{2} /(\mathrm{V} \mathrm{s})$ at $2 \mathrm{~K}$. The high in-plane room temperature mobility is consistent with the electronic structure calculations, and suggests $\mathrm{Bi}_{4} \mathrm{O}_{4} \mathrm{SeCl}_{2}$ as a viable candidate for two-dimensional semiconductor applications.

Below $10 \mathrm{~K}$ the resistivity starts increasing as the temperature decreases, which is a signature of weak localization. This is confirmed with a combination of positive nonsaturating quadratic magnetoresistance dominating at high field due to free carriers in an open orbit and a negative contribution at low field due to the weak localization effect (Figure 6b). The negative contribution disappears above $60 \mathrm{~K}$, confirming a quantum origin and ruling out ionised impurity magnetoresistance. It is worth noting that a more negative magnetoresistance is observed when the field is applied parallel to the $a b$ plane, and hence parallel to the anion disordered Se/ $\mathrm{Cl}$ plane, suggesting that the origin of the weak localization is the chemical site disorder of $\mathrm{Se}$ and $\mathrm{Cl}$, rather than impurities and dislocations. This is consistent with the wave functions at the conduction band minimum being $\mathrm{Bi} 6 \mathrm{p}$ states that are nonbonding with the bridging anion and thus only slightly affected by the anion site occupancy disorder which stabilizes the material thermodynamically. Because this is a weak effect that only manifests as quantum interference, above $60 \mathrm{~K}$ the conduction electrons are only weakly affected by this disorder this disorder due to protection by symmetry.

Because of the van der Waals gap in the crystal structure, the potential of $\mathrm{Bi}_{4} \mathrm{O}_{4} \mathrm{SeCl}_{2}$ as a van der Waals material that undergoes exfoliation was explored by total energy calculations. Here the unit cell is elongated and the structure is allowed to relax; the energy, which includes a van der Waals contribution, will increase toward a plateau as the layers are separated (Figure 6a). The energy to separate two layers of $\mathrm{Bi}_{2} \mathrm{O}_{2} \mathrm{Se}$ is $0.5 \mathrm{eV} /$ surface atom $\left(0.53 \mathrm{~J} / \mathrm{m}^{2}\right)$, while for $\mathrm{Bi}_{4} \mathrm{O}_{4} \mathrm{SeCl}_{2}$ (and $\mathrm{BiOCl}$ ) it is $0.2 \mathrm{eV} /$ surface atom $(0.21 \mathrm{~J} /$ $\mathrm{m}^{2}$ ), indicating that it is significantly easier to separate layers of $\mathrm{Bi}_{4} \mathrm{O}_{4} \mathrm{SeCl}_{2}$. Including the effect of disorder only slightly increases the calculated exfoliation energy by $0.02 \mathrm{~J} / \mathrm{m}^{2}$ (Supplementary Figure 14). The same calculation for $\mathrm{BiOCl}$ shows an almost identical exfoliation behavior to that of $\mathrm{Bi}_{4} \mathrm{O}_{4} \mathrm{SeCl}_{2}$, indicating that the exfoliation behavior is indeed controlled by the van der Waals gap interface, which is structurally the same in both materials.

Consistent with this, the calculations were strongly affected by removing the van der Waals component of the energy in the $\mathrm{Bi}_{4} \mathrm{O}_{4} \mathrm{SeCl}_{2}$ and $\mathrm{BiOCl}$ cases, but not in the case of $\mathrm{Bi}_{2} \mathrm{O}_{2} \mathrm{Se}$, where changes in the nondispersion interactions are dominant upon separation of the layers. The relaxed structures at high separation show that $\mathrm{Bi}_{2} \mathrm{O}_{2} \mathrm{Se}$ reconstructs at the Se interface, with half of the Se atoms going to the top layer and the other half going to the bottom layer, consistent with the surface termination measured by Chen et al. ${ }^{28}$ Because of the breaking of the bonds, the resulting $\mathrm{Bi}_{2} \mathrm{O}_{2} \mathrm{Se}$ layer undergoes significant reconstruction when the structure is relaxed (Supplementary Figures 12 and 13). As such, creating the superlattice allows for a combination of the mechanical exfoliation properties of $\mathrm{BiOCl}$ with the electronic properties of $\mathrm{Bi}_{2} \mathrm{O}_{2} \mathrm{Se}$. 
a
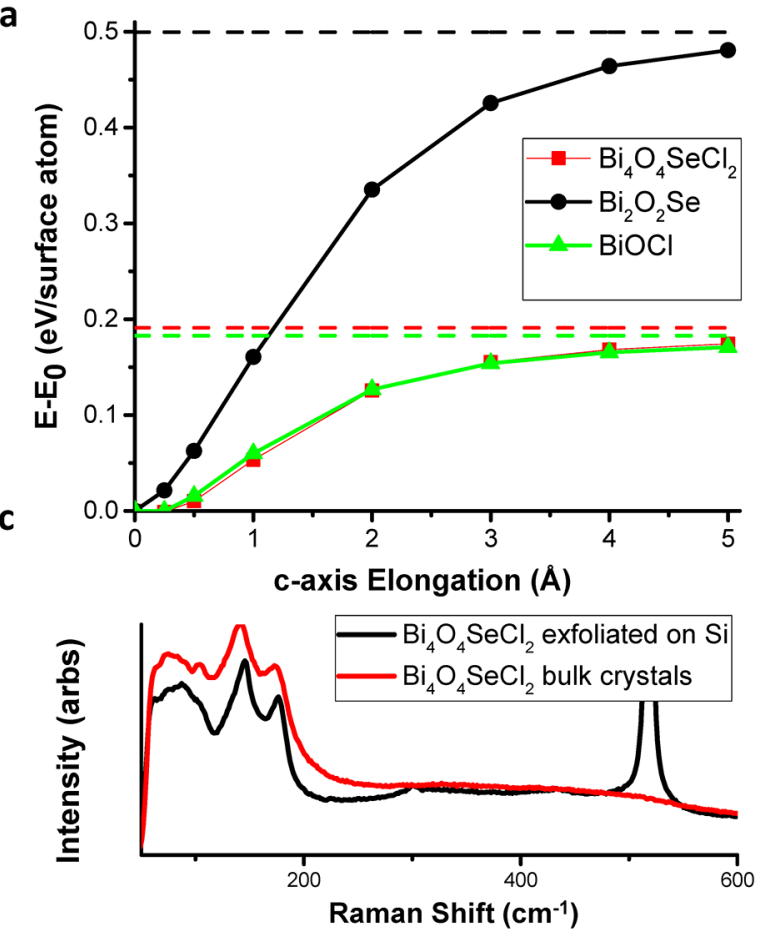

b
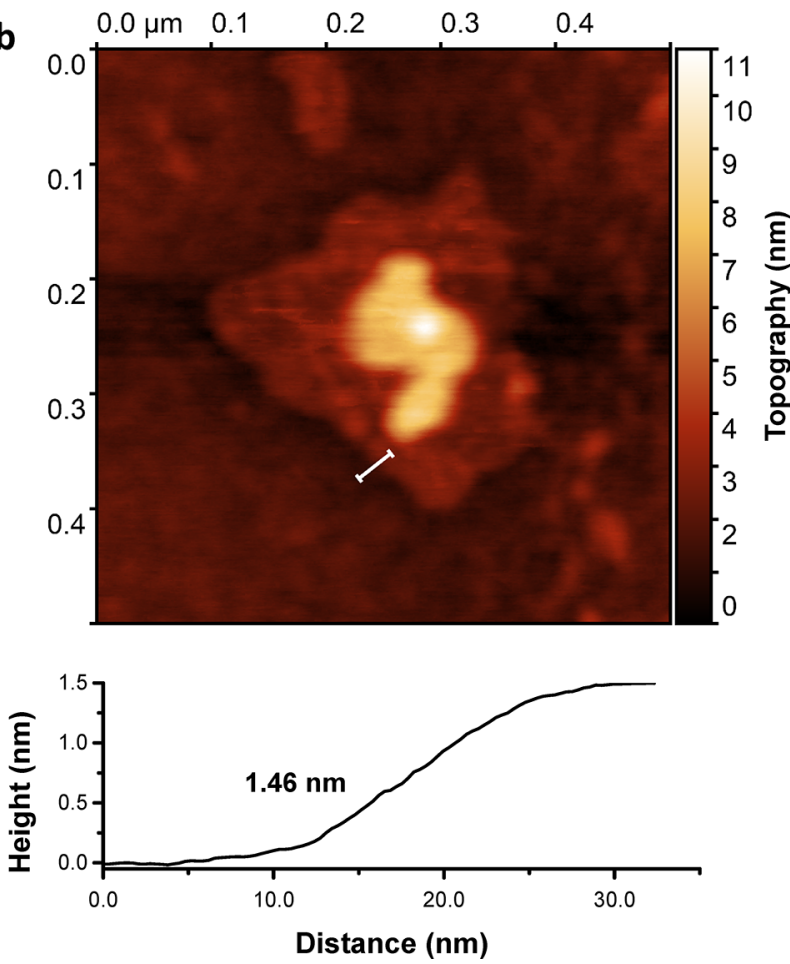

Figure 7. (a) Energy versus $c$-axis elongation for $\mathrm{Bi}_{4} \mathrm{O}_{4} \mathrm{SeCl}_{2}$ compared with $\mathrm{Bi}_{2} \mathrm{O}_{2} \mathrm{Se}$ and $\mathrm{BiOCl}$, showing the interlayer binding strength. (b) AFM image of a monolayer flake of $\mathrm{Bi}_{4} \mathrm{O}_{4} \mathrm{SeCl}_{2}$ with the height profile corresponding to the line cut. The total height of this line cut is $1.46 \mathrm{~nm}(\mathrm{c})$ Comparison of the Raman spectrum of the bulk crystals (red) and tape exfoliated multilayer flakes (blue) on native oxide $\mathrm{Si}$, both taken with a 532 $\mathrm{nm}$ laser. The intense peak near $500 \mathrm{~nm}$ is background from the substrate.

The energy to separate two layers for $\mathrm{Bi}_{4} \mathrm{O}_{4} \mathrm{SeCl}_{2}$ of $\sim 0.2 \mathrm{~J} /$ $\mathrm{m}^{2}$ is consistent with that calculated for other exfoliatable van der Waals materials, such as $\mathrm{CrOCl}$, and lower than that calculated for graphite $\left(0.21 \mathrm{~J} / \mathrm{m}^{2}\right.$ and $0.3 \mathrm{~J} / \mathrm{m}^{2}$, respectively). ${ }^{29}$ This value is not expected to be precise, as the binding energy of the layer varies significantly depending on the functional used. ${ }^{30}$ However, it does indicate a much reduced layer binding energy for $\mathrm{Bi}_{4} \mathrm{O}_{4} \mathrm{SeCl}_{2}$ compared to $\mathrm{Bi}_{2} \mathrm{O}_{2} \mathrm{Se}$.

Electronic structure calculations performed on an idealized two-dimensional slab of $\mathrm{Bi}_{4} \mathrm{O}_{4} \mathrm{SeCl}_{2}$ (Supplementary Figure 20) show that the conduction and valence bands arise from the same states as in the bulk, with similar features and dispersions, with a $0.87 \mathrm{eV}$ indirect band gap, as calculated by SCAN+SOC (compared to $0.79 \mathrm{eV}$ for the bulk material) and an electron effective mass of $0.22(1) m_{\mathrm{e}}$. Therefore, a two-dimensional slab (corresponding to half a unit cell along $c$ in Figure 1c) should retain high mobility semiconductor properties. As such, electronic measurements on exfoliated $\mathrm{Bi}_{4} \mathrm{O}_{4} \mathrm{SeCl}_{2}$ would be of considerable future interest.

Large single crystals were affixed to Scotch tape and exfoliated by repeated removal of the tape until the crystals were semitransparent. At this point, the crystals were transferred onto a Si substrate. The resulting exfoliated crystals were measured by atomic force microscopy (AFM). Figure $7 \mathrm{~b}$ shows a height map of an exfoliated crystal, along with a line cut showing the flake to be one layer thick, where one layer is a half a unit cell (Figure 1c), or approximately $1.4 \mathrm{~nm}$ in height; this represents the distance between two van der Waals gaps and therefore the thinnest charge-neutral unit that can be expected to exfoliate. This layer thickness was confirmed by the height of the step edges in AFM measurements on thicker flakes (Supplementary Figure 16). The Raman spectrum of the exfoliated material (Figure $7 \mathrm{c}$ ) retains features at the same frequencies as the bulk, confirming that the material has remained intact. Small shifts in intensity and position of Raman peaks are expected when going from a bulk material to a monolayer, as observed for $\mathrm{MoS}_{2}{ }^{31}$ The presence of $\mathrm{Bi}$ and $\mathrm{Se}$ in the flakes was also confirmed by energy dispersive X-ray spectroscopy (EDX) and X-ray photoelectron spectroscopy (XPS) mapping (Supplementary Figure 18). Electron diffraction on the tape-exfoliated material (Figure 8) shows a square lattice with an interatomic distance of 2.5(1) $\AA$, which is slightly smaller than but consistent with the $\mathrm{Bi}-\mathrm{Bi}$ distances as projected down the $(0,0,1)$ axis (Supplementary Figure 17).
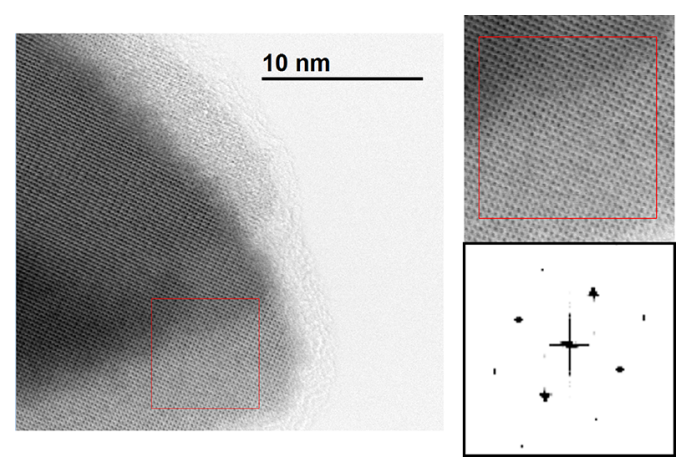

Figure 8. TEM image (left) and fast Fourier transform with an enlarged view of the area (right) of a tape exfoliated crystal of $\mathrm{Bi}_{4} \mathrm{O}_{4} \mathrm{SeCl}_{2}$, showing a retention of the square lattice down the [001] direction and a lattice spacing consistent with the $\mathrm{Bi}-\mathrm{Bi}$ distances in the crystal structure projected down the [001] axis. 


\section{CONCLUSIONS}

Reduction in the bonding dimensionality of three dimensionally connected layered structures is a chemical route to new families of van der Waals materials. Here we have shown this by the modular design concept of introducing a van der Waals gap into a material by making an entropy stabilized superlattice with a different module that contains a van der Waals gap and does not interfere with the electronic properties We demonstrate that this can be achieved by enhancing anion chemical diversity and thus the number of bond types present in the stacking sequence. Bridging selenide anions connect the $\mathrm{Bi}_{2} \mathrm{O}_{2}{ }^{2+}$ slabs in structurally layered $\mathrm{Bi}_{2} \mathrm{O}_{2} \mathrm{Se}$, forming a network of interlayer bonds in the third dimension. Introduction of chloride as a third anion interrupts this network and reduces the bonding dimensionality, affording the van der Waals high mobility semiconductor $\mathrm{Bi}_{4} \mathrm{O}_{4} \mathrm{SeCl}_{2}$. The terminally bonded chlorides in $\mathrm{Bi}_{4} \mathrm{O}_{4} \mathrm{SeCl}_{2}$ replace half of the selenides in $\mathrm{Bi}_{2} \mathrm{O}_{2} \mathrm{Se}$ (Figure 1). While the selenide and chloride anions mix, producing an entropy driven stabilizing effect, the structural units present in $\mathrm{Bi}_{2} \mathrm{O}_{2} \mathrm{Se}$ and $\mathrm{BiOCl}$ are retained. This retains the electronic structure and properties of the parent defined by the bridging anion layers, and introduces a van der Waals gap between adjacent chloride layers to allow exfoliation of $\mathrm{Bi}_{4} \mathrm{O}_{4} \mathrm{SeCl}_{2}$ to $1.4 \mathrm{~nm}$ thick sheets, half the height of the crystallographic unit cell. This inserted van der Waals gap is thermodynamically stabilized by occupancy disorder across the two chemically distinct sites, generating the entropystabilized superlattice phase $\mathrm{Bi}_{4} \mathrm{O}_{4} \mathrm{SeCl}_{2} . \mathrm{Bi}_{4} \mathrm{O}_{4} \mathrm{SeCl}_{2}$ is therefore a good candidate material for study as a new air-stable $2 \mathrm{D}$ semiconductor.

\section{EXPERIMENTAL SECTION}

The $\mathrm{Bi}_{4} \mathrm{O}_{4} \mathrm{SeCl}_{2}$ composition can be prepared as a single phase powder. $\mathrm{Bi}_{4} \mathrm{O}_{4} \mathrm{SeCl}_{2}$ was synthesized from a stoichiometric mixture of $\mathrm{BiOCl}, \mathrm{Bi}, \mathrm{Bi}_{2} \mathrm{O}_{3}$, and $\mathrm{Se}$ powder sealed in an evacuated quartz ampule and heated at $800{ }^{\circ} \mathrm{C}$ for $12 \mathrm{~h}$, followed by regrinding and a second identical heating step. Small single crystals were isolated from the powder for X-ray diffraction measurements, affording a cell of $a=$ 3.8995(8) Å, $c=26.968(5) \AA$ in space group $I 4 / \mathrm{mmm}$ which allowed complete indexing and Pawley refinement (Supplementary Figure 1) of the bulk powder pattern to confirm phase purity. WDX measurements, using $\mathrm{BiOCl}$ and $\mathrm{Bi}_{2} \mathrm{O}_{2} \mathrm{Se}$ as standards, revealed a composition of $\mathrm{Bi}_{3.9(3)} \mathrm{O}_{4.0(3)} \mathrm{SeCl}_{1.9(2)}$, which is within error of the expected nominal composition $\mathrm{Bi}_{4} \mathrm{O}_{4} \mathrm{SeCl}_{2}$. Multiple crystallites of the sample were measured, showing a narrow compositional range (Supplementary Figure 2). The material showed no sign of degradation on standing in laboratory air for 1 week, when submerged in water for $24 \mathrm{~h}$, or when exposed to simulated solar radiation for 24 h. The growth of single crystals is described in the Supporting Information.

The stability of $\left(\mathrm{Bi}_{2} \mathrm{O}_{2} \mathrm{Cl}_{2-x} \mathrm{Se}_{x}\right)\left(\mathrm{Bi}_{2} \mathrm{O}_{2} \mathrm{Se}_{1-x} \mathrm{Cl}_{x}\right)$ as compared to its building blocks was calculated by dividing the chemical reaction into two steps, i.e., separating

(1) $\mathrm{Bi}_{2} \mathrm{O}_{2} \mathrm{Se}+2 \mathrm{BiOCl}=\mathrm{Bi}_{2} \mathrm{O}_{2} \mathrm{Cl}_{2-x} \mathrm{Se}_{x} \mathrm{Bi}_{2} \mathrm{O}_{2} \mathrm{Se}_{1-x} \mathrm{Cl}_{x}$ into

$$
\begin{gathered}
\mathrm{Bi}_{2} \mathrm{O}_{2} \mathrm{Se}+2 \mathrm{BiOCl}=\mathrm{Bi}_{4} \mathrm{O}_{4} \mathrm{Cl}_{2} \mathrm{Se} \\
+ \\
\mathrm{Bi}_{4} \mathrm{O}_{4} \mathrm{Cl}_{2} \mathrm{Se}=\mathrm{Bi}_{2} \mathrm{O}_{2} \mathrm{Cl}_{2-x} \mathrm{Se}_{x} \mathrm{Bi}_{2} \mathrm{O}_{2} \mathrm{Se}_{1-x} \mathrm{Cl}_{x}
\end{gathered}
$$

Total energy calculations were performed using VASP to calculate the enthalpy changes of steps 2 and $3 .^{32}$ The enthalpy change for step 2 was calculated to be $+0.46 \mathrm{meV} /$ atom. The cutoff energy of plane wave basis set was set to $550 \mathrm{eV}$. The van der Waals interaction was included with the optB86b-vdW functional. ${ }^{33}$ In order to consider the positional randomness of $\mathrm{Cl}$ and $\mathrm{Se}$ atoms in $\mathrm{Bi}_{2} \mathrm{O}_{2} \mathrm{Cl}_{2-x} \mathrm{Se}_{x}$. $\mathrm{Bi}_{2} \mathrm{O}_{2} \mathrm{Se}_{1-x} \mathrm{Cl}_{x}, 4 \times 4 \times 1$ supercells with 352 atoms were built based on the optimized structure of perfect $\mathrm{Bi}_{4} \mathrm{O}_{4} \mathrm{Cl}_{2} \mathrm{Se}$. Eight random configurations, wherein random $\mathrm{Cl}$ and $\mathrm{Se}$ atoms in each layer were chosen as defect sites with a random number generating Python algorithm (with the constraint that each layer has the same overall defect concentration), were built for $\mathrm{Bi}_{2} \mathrm{O}_{2} \mathrm{Cl}_{2-x} \mathrm{Se}_{x} \cdot \mathrm{Bi}_{2} \mathrm{O}_{2} \mathrm{Se}_{1-x} \mathrm{Cl}_{x}$ with $x$ ranging from 0 to $1 . \mathrm{Bi}_{4} \mathrm{O}_{4} \mathrm{Cl}_{2} \mathrm{Se}, \mathrm{Bi}_{2} \mathrm{O}_{2} \mathrm{Se}$, and $\mathrm{BiOCl}$ unit cells were optimized with Monkhost-Pack $k$ mesh of $7 \times 7 \times 1,9 \times 9$ $\times 4$, and $9 \times 9 \times 5$, respectively. Supercells were optimized with $\Gamma$ point-only calculations. As there are four $\mathrm{Cl}$ atomic layers and two Se atomic layers in the unit cell, the configurational entropy was calculated as

$$
\begin{aligned}
\Delta S= & \left\{-4 N_{\mathrm{Cl}} k_{\mathrm{B}}\left[x_{\mathrm{Se}} \ln \left(x_{\mathrm{Se}}\right)+\left(1-x_{\mathrm{Se}}\right) \ln \left(1-x_{\mathrm{Se}}\right)\right]\right. \\
& \left.-2 N_{\mathrm{Se}} k_{\mathrm{B}}\left[x_{\mathrm{Cl}} \ln \left(x_{\mathrm{Cl}}\right)+\left(1-x_{\mathrm{Cl}}\right) \ln \left(1-x_{\mathrm{Cl}}\right)\right]\right\} / N_{\text {total }}
\end{aligned}
$$

where $N_{\mathrm{Cl}}$ is the number of $\mathrm{Cl}$ sites in the $\mathrm{Cl}$ atomic layer, $N_{\mathrm{Se}}$ is the number of Se sites in the Se atomic layer, $N_{\text {total }}$ is the total number of atoms in the supercell, $x_{\mathrm{Cl}}=\mathrm{x}$, and $x_{\mathrm{Se}}=\mathrm{x} / 2$.

All calculations were performed using periodic, plane-wave based, density functional theory as implemented in VASP. ${ }^{32}$ Core electrons were treated using the projector augmented wave approach. ${ }^{34}$ Structural optimization was performed using the meta-GGA functional SCAN $+\mathrm{rVV}^{35} 0^{35}$ which includes nonlocal correlation to better describe van der Waals interactions. Improved values of the band gaps were obtained using single-point calculations with the HSE06 hybrid functional ${ }^{36}$ with spin-orbit coupling (HSE06+SOC) on reduced $k$ point grids (Supplementary Table 7) and a plane-wave cutoff energy of $400 \mathrm{eV}$. Full computational details can be found in the Supporting Information.

Diffuse reflectance measurements were taken on powdered samples of $\mathrm{BiOCl}, \mathrm{Bi}_{2} \mathrm{O}_{2} \mathrm{Se}$, and $\mathrm{Bi}_{4} \mathrm{O}_{4} \mathrm{SeCl}_{2}$ using a Cary 5000 UV-vis-NIR spectrometer. Transmission experiments were performed on Scotch tape cleaved samples, such that the crystals were sufficiently thin, on a Bruker Vertex $70 \mathrm{~V}$ Fourier transform infrared spectrometer, using a mid-infrared source, $\mathrm{KBr}$ beamsplitter, and deuterated L-alanine doped triglycene (DLaTGS) pyroelectric detector. X-ray photoelectron spectroscopy measurements were conducted using a monochromatic $\mathrm{Al} \mathrm{K} \alpha$ SPECS $(h \nu=1486.7 \mathrm{eV})$ X-ray source operated at $250 \mathrm{~W}$. Full details can be found in the Supporting Information.

The magneto-transport properties were measured on a single crystal using the van der Pauw method. Four indium contacts were soldered on the edge of the crystal with the current and voltage lead configured for measuring both the longitudinal and transverse magnetoresistance between -10 and $10 \mathrm{~T}$ using the ETO option of the MPMS Dynacool system with an AC excitation of $3 \mathrm{~mA}$. The antisymmetric part of the transverse magnetoresistance was used to extract the Hall resistance and the symmetric part of the longitudinal magnetoresistance was used to extract the conventional magnetoresistance.

$\mathrm{Bi}_{4} \mathrm{O}_{4} \mathrm{Cl}_{2} \mathrm{Se}$ was exfoliated using the well-established "Scotch tape" method. ${ }^{37}$ Crystals of the material were placed onto a strip of Scotch tape, and a new strip of Scotch tape was pressed onto the crystals and removed. This process was repeated on each subsequent new piece of Scotch tape until the material was difficult to see by eye, approximately eight times. The final piece of Scotch tape containing thin flakes of material was pressed firmly onto a fragment of native oxide $\mathrm{Si}$ wafer ranging from 1 to $2 \mathrm{~cm} \times 1$ to $2 \mathrm{~cm}$, cleaned by sonication in propan-2-ol, and dried in a stream of nitrogen. The Scotch tape was slowly removed from the surface of the Si to transfer the material. An optical microscope inspection confirmed the transfer of larger flakes of material. AFM was used to determine the thickness of the flakes.

AFM measurements were performed using an Agilent 5600LS atomic force microscope using tapping mode and Keysight Technologies PicoView control software v1.20.3. Image processing 
was performed using Gwyddion SPM visualization and analysis software v2.39.

Raman spectroscopy was performed on a Renishaw InVia Qontor confocal Raman microscope using a $532 \mathrm{~nm}$ excitation source and $100 \times$ objective lens. Raman mapping images of the Scotch tape exfoliated flakes on $\mathrm{Si}$ wafers were obtained at $1 \mu \mathrm{m}$ intervals with 1000 accumulations per pixel for a large area scan and 2000 accumulations for a smaller area scan. Data was processed using Renishaw WiRE software.

The data as presented in this paper is freely available at http:// datacat.liverpool.ac.uk/id/eprint/901.

\section{ASSOCIATED CONTENT}

\section{S Supporting Information}

The Supporting Information is available free of charge at https://pubs.acs.org/doi/10.1021/jacs.9b09411.

Crystallographic information for $\mathrm{Bi}_{4} \mathrm{O}_{4} \mathrm{SeC}_{12}$ (CIF) Synthesis, phase purity, and composition; crystal structure solution; Raman spectroscopy; disorder and entropy stabilization; electronic structure; optical measurements; exfoliation (PDF)

\section{AUTHOR INFORMATION}

\section{Corresponding Author}

*m.j.rosseinsky@liverpool.ac.uk

\section{ORCID $\odot$}

Matthew J. Rosseinsky: 0000-0002-1910-2483

Notes

The authors declare no competing financial interest.

\section{ACKNOWLEDGMENTS}

The authors acknowledge support from the EPSRC (EP/ N004884). Access to the national HPC resource, Archer, was provided through the EPSRC program grant (EP/N004884), and other HPC resources were provided by the University of Liverpool. R.R. and F.M. thank the BBSRC (BB/R012415/1) and Innovate UK (TS/P013716/1Z) for support. M.J.R. thanks the Royal Society for the award of a Research Professorship. The authors would like to thank Harry Sansom for performing initial EDX measurements.

\section{REFERENCES}

(1) McKinney, R. W.; Gorai, P.; Manna, S.; Toberer, E.; Stevanović, V. Ionic vs. van der Waals layered materials: identification and comparison of elastic anisotropy. J. Mater. Chem. A 2018, 6 (32), $15828-15838$.

(2) Manzeli, S.; Ovchinnikov, D.; Pasquier, D.; Yazyev, O. V.; Kis, A. 2D transition metal dichalcogenides. Nat. Rev. Mater. 2017, 2 (8), 17033.

(3) Ziatdinov, M.; Banerjee, A.; Maksov, A.; Berlijn, T.; Zhou, W.; Cao, H.; Yan, J.-Q.; Bridges, C. A.; Mandrus, D.; Nagler, S. E.; et al. Atomic-scale observation of structural and electronic orders in the layered compound $\alpha-\mathrm{RuCl}_{3}$. Nat. Commun. 2016, 7, 13774.

(4) Chen, B.; Yang, J.; Wang, H.; Imai, M.; Ohta, H.; Michioka, C.; Yoshimura, K.; Fang, M. Magnetic properties of layered itinerant electron ferromagnet $\mathrm{Fe}_{3} \mathrm{GeTe}_{2}$. J. Phys. Soc. Jpn. 2013, 82 (12), 124711.

(5) Harada, J. K.; Charles, N.; Poeppelmeier, K. R.; Rondinelli, J. M. Materials Design: Heteroanionic Materials by Design: Progress Toward Targeted Properties (Adv. Mater. 19/2019). Adv. Mater. 2019, 31 (19), 1970134.

(6) Kageyama, H.; Hayashi, K.; Maeda, K.; Attfield, J. P.; Hiroi, Z.; Rondinelli, J. M.; Poeppelmeier, K. R. Expanding frontiers in materials chemistry and physics with multiple anions. Nat. Commun. 2018, 9 (1), 772 .
(7) Novoselov, K. S.; Mishchenko, A.; Carvalho, A.; Castro Neto, A. H. 2D materials and van der Waals heterostructures. Science 2016, 353 (6298), No. aac9439.

(8) Mas-Balleste, R.; Gomez-Navarro, C.; Gomez-Herrero, J.; Zamora, F. 2D materials: to graphene and beyond. Nanoscale 2011, $3(1), 20-30$

(9) Schwierz, F. Graphene transistors. Nat. Nanotechnol. 2010, 5 (7), 487.

(10) Liu, H.; Du, Y.; Deng, Y.; Ye, P. D. Semiconducting black phosphorus: synthesis, transport properties and electronic applications. Chem. Soc. Rev. 2015, 44 (9), 2732-2743.

(11) Singh, A. K.; Mathew, K.; Zhuang, H. L.; Hennig, R. G. Computational screening of $2 \mathrm{D}$ materials for photocatalysis. J. Phys. Chem. Lett. 2015, 6 (6), 1087-1098.

(12) Larsen, P. M.; Pandey, M.; Strange, M.; Jacobsen, K. W. Definition of a scoring parameter to identify low-dimensional materials components. Phys. Rev. Mater. 2019, 3 (3), 034003.

(13) Juza, R.; Langer, K. Ternäre Phosphide und Arsenide des Lithiums mit Eisen, Kobalt oder Chrom im $\mathrm{Cu}_{2}$ Sb-Typ. Z. Anorg. Allg. Chem. 1968, $361(1-2), 58-73$.

(14) Fu, Q.; Zhu, C.; Zhao, X.; Wang, X.; Chaturvedi, A.; Zhu, C.; Wang, X.; Zeng, Q.; Zhou, J.; Liu, F.; et al. Ultrasensitive $2 \mathrm{D} \mathrm{Bi}_{2} \mathrm{O}_{2} \mathrm{Se}$ phototransistors on silicon substrates. Adv. Mater. 2019, 31 (1), 1804945.

(15) Wu, J.; Liu, Y.; Tan, Z.; Tan, C.; Yin, J.; Li, T.; Tu, T.; Peng, H. Chemical Patterning of High-Mobility Semiconducting 2D $\mathrm{Bi}_{2} \mathrm{O}_{2} \mathrm{Se}$ Crystals for Integrated Optoelectronic Devices. Adv. Mater. 2017, 29 (44), 1704060.

(16) Wu, J.; Yuan, H.; Meng, M.; Chen, C.; Sun, Y.; Chen, Z.; Dang, W.; Tan, C.; Liu, Y.; Yin, J.; et al. High electron mobility and quantum oscillations in non-encapsulated ultrathin semiconducting $\mathrm{Bi}_{2} \mathrm{O}_{2} \mathrm{Se}$. Nat. Nanotechnol. 2017, 12 (6), 530.

(17) Schmidt, P.; Oppermann, H.; Söger, N.; Binnewies, M.; Rykov, A.; Znamenkov, K.; Kuznetzov, A.; Popovkin, B. Gasphasengleichgewichte quaternärer Bismut-Selen-Oxidchloride. Z. Anorg. Allg. Chem. 2000, 626 (12), 2515-2524.

(18) Nakajima, S. The crystal structure of $\mathrm{Bi}_{2} \mathrm{Te}_{3-x} \mathrm{Se}_{\mathrm{x}}$.J. Phys. Chem. Solids 1963, 24 (3), 479-485.

(19) Pereira, A. L.; Santamaría-Pérez, D.; Ruiz-Fuertes, J.; Manjón, F.; Cuenca-Gotor, V.; Vilaplana, R.; Gomis, O.; Popescu, C.; Muñoz, A.; Rodríguez-Hernández, P.; et al. Experimental and theoretical Study of $\mathrm{Bi}_{2} \mathrm{O}_{2} \mathrm{Se}$ under compression. J. Phys. Chem. C 2018, 122 (16), 8853-8867.

(20) Yang, X.; Zhang, Y. Prediction of high-entropy stabilized solidsolution in multi-component alloys. Mater. Chem. Phys. 2012, 132 (2-3), 233-238.

(21) Rost, C. M.; Sachet, E.; Borman, T.; Moballegh, A.; Dickey, E. C.; Hou, D.; Jones, J. L.; Curtarolo, S.; Maria, J.-P. Entropy-stabilized oxides. Nat. Commun. 2015, 6, 8485.

(22) Gibson, Q. D.; Dyer, M. S.; Robertson, C.; Delacotte, C.; Manning, T. D.; Pitcher, M. J.; Daniels, L. M.; Zanella, M.; Alaria, J.; Claridge, J. B.; et al. $\mathrm{Bi}_{2+2} \mathrm{O}_{2+2 \mathrm{n}} \mathrm{Cu}_{2-\delta} \mathrm{Se}_{2+\mathrm{n}-\delta} \mathrm{X}_{\delta}(\mathrm{X}=\mathrm{Cl}, \mathrm{Br})$ : A ThreeAnion Homologous Series. Inorg. Chem. 2018, 57 (20), 1248912500 .

(23) Kabbour, H.; Cario, L. $\mathrm{Ae}_{2} \mathrm{Sb}_{2} \mathrm{X}_{4} \mathrm{~F}_{2}(\mathrm{Ae}=\mathrm{Sr}, \mathrm{Ba})$ : New Members of the Homologous Series $\mathrm{Ae}_{2} \mathrm{M}_{1+\mathrm{n}} \mathrm{X}_{3+\mathrm{n}} \mathrm{F}_{2}$ Designed from Rock Salt and Fluorite 2D Building Blocks. Inorg. Chem. 2006, 45 (6), 2713-2717.

(24) Kusainova, A. M.; Lightfoot, P.; Zhou, W.; Stefanovich, S. Y.; Mosunov, A. V.; Dolgikh, V. A. Ferroelectric properties and crystal structure of the layered intergrowth phase $\mathrm{Bi}_{3} \mathrm{~Pb}_{2} \mathrm{Nb}_{2} \mathrm{O}_{11} \mathrm{Cl}$. Chem. Mater. 2001, 13 (12), 4731-4737.

(25) Fujito, H.; Kunioku, H.; Kato, D.; Suzuki, H.; Higashi, M.; Kageyama, $\mathrm{H}$.; Abe, R. Layered perovskite oxychloride $\mathrm{Bi}_{4} \mathrm{NbO}_{8} \mathrm{Cl}$ : a stable visible light responsive photocatalyst for water splitting. J. Am. Chem. Soc. 2016, 138 (7), 2082-2085.

(26) Scofield, J. H. Theoretical photoionization cross sections from 1 to $1500 \mathrm{keV}$; Lawrence Livermore Laboratory, Univesrity of California: Livermore, CA, 1973. 
(27) Fang, H.; Chuang, S.; Chang, T. C.; Takei, K.; Takahashi, T.; Javey, A. High-performance single layered $\mathrm{WSe}_{2}$ p-FETs with chemically doped contacts. Nano Lett. 2012, 12 (7), 3788-3792.

(28) Chen, C.; Wang, M.; Wu, J.; Fu, H.; Yang, H.; Tian, Z.; Tu, T.; Peng, H.; Sun, Y.; Xu, X.; et al. Electronic structures and unusually robust bandgap in an ultrahigh-mobility layered oxide semiconductor, $\mathrm{Bi}_{2} \mathrm{O}_{2}$ Se. Science Adv. 2018, 4 (9), No. eaat8355.

(29) Miao, N.; Xu, B.; Zhu, L.; Zhou, J.; Sun, Z. 2D intrinsic ferromagnets from Van der Waals antiferromagnets. J. Am. Chem. Soc. 2018, 140 (7), 2417-2420.

(30) Björkman, T.; Gulans, A.; Krasheninnikov, A. V.; Nieminen, R. M. van der Waals bonding in layered compounds from advanced density-functional first-principles calculations. Phys. Rev. Lett. 2012, 108 (23), 235502.

(31) Li, H.; Zhang, Q.; Yap, C. C. R.; Tay, B. K.; Edwin, T. H. T.; Olivier, A.; Baillargeat, D. From bulk to monolayer $\mathrm{MoS}_{2}$ : evolution of Raman scattering. Adv. Funct. Mater. 2012, 22 (7), 1385-1390.

(32) Kresse, G.; Furthmüller, J. Software VASP, vienna (1999). Phys. Rev. B 1996, 54 (11), 169.

(33) Klimešs, J.; Bowler, D. R.; Michaelides, A. Van der Waals density functionals applied to solids. Phys. Rev. B: Condens. Matter Mater. Phys. 2011, 83 (19), 195131.

(34) Kresse, G.; Joubert, D. From ultrasoft pseudopotentials to the projector augmented-wave method. Phys. Rev. B: Condens. Matter Mater. Phys. 1999, 59 (3), 1758.

(35) Peng, H.; Yang, Z.-H.; Perdew, J. P.; Sun, J. Versatile van der Waals density functional based on a meta-generalized gradient approximation. Phys. Rev. X 2016, 6 (4), 041005.

(36) Krukau, A. V.; Vydrov, O. A.; Izmaylov, A. F.; Scuseria, G. E. Influence of the exchange screening parameter on the performance of screened hybrid functionals. J. Chem. Phys. 2006, 125 (22), 224106.

(37) Yi, M.; Shen, Z. A review on mechanical exfoliation for the scalable production of graphene. J. Mater. Chem. A 2015, 3 (22), $11700-11715$. 